Research Article

\title{
Conductivity, Surface Tension, and Comparative Antibacterial Efficacy Study of Different Brands of Soaps of Nepal
}

\author{
Narendra Kumar Chaudhary (D), Arush Bhattarai, Biswash Guragain (iD, \\ and Ajaya Bhattarai \\ Department of Chemistry, Tribhuvan University, Mahendra Morang Adarsh Multiple Campus, Biratnagar, Nepal \\ Correspondence should be addressed to Ajaya Bhattarai; bkajaya@yahoo.com
}

Received 18 June 2019; Revised 27 January 2020; Accepted 26 February 2020; Published 15 April 2020

Academic Editor: Elena Gomez

Copyright (c) 2020 Narendra Kumar Chaudhary et al. This is an open access article distributed under the Creative Commons Attribution License, which permits unrestricted use, distribution, and reproduction in any medium, provided the original work is properly cited.

\begin{abstract}
The current study aims to evaluate the solution properties and antibacterial efficacy study of five different brands of toilet soaps of Nepal such as Okhati (OKT), Lifebuoy (LFBY), Lux (LX), Liril (LRL), and Chiuree Neem (NM). The evaluation of critical micelle concentration $(\mathrm{CMC})$ and their thermodynamics and surface properties are also reported. This study was further extended to evaluate antibacterial efficacy against three pathogenic bacteria such as Staphylococcus aureus (S. aureus), Escherichia coli (E. coli), and Proteus vulgaris (P. vulgaris) by disc diffusion technique, and it was done at four different concentrations of soap. The bioactive ingredients present in them provide antibacterial potency to cure various skin problems caused by bacterial pathogens. Similarly, the antibacterial potency of LFBY was found higher than other soaps. Based on these studies, we can simply take LFBY soap at the highest rank in regards to antibacterial sensitivity.
\end{abstract}

\section{Introduction}

The prevalence of skin diseases is increasing due to the direct interaction of transient microorganisms on the skin surface. If not degermed properly they penetrate the human body and cause internal infection. So, degerming of the body is a matter of prime importance to maintain personal hygiene. The simplest and effective way to prevent the spread of microbial infections is proper cleaning and washing of body parts using soap [1]. The soap contains surfactants and antimicrobial ingredients to enhance the cleansing action and wash pathogenic organisms. It is one of the mild detergents [2], which is effective in removing contaminants including bacteria, fungus, or viruses. Soap solution acts upon the alien particles, emulsifies, and suspends the dirt, oil, and germs, allowing them to be washed off. For further protection, either chemical or plant-based antibacterial agents are used in soaps to enhance biofunctional activities. Chemicals like triclocarban and triclosan are added in soap and personal care products alike as antibacterial ingredients. These antibacterial ingredients of soap are effective in preventing communicable diseases [3]. 65\%-85\% microbial removal from human skin is due to the application of antibacterial soap $[4,5]$.

A study by Riaz et al. [6] revealed greater effectiveness of antibacterial soaps against pathogenic bacteria relative to plain soaps. Typically, antimicrobial products are used to stay healthy. However, there are two risks of their use; the first is deliberately accepted chemical exposure and the next is the increase of antibiotic-resistant pathogens, which ultimately makes the microbial treatment more difficult. As per a review, Aiello et al. [7] observed that the available data did not support the effectiveness of triclosan for reducing symptoms of infectious disease which is a common antibacterial used in soap. As recommended by the Food and Drug Administration (FDA), the effectiveness of the antiseptic ingredients should be studied reflecting exposure time and real-life situations. Kim et al. [3] studied the antibacterial effect of some plain and antibacterial soaps against 20 bacterial strains proposed by the FDA. Under real-life conditions, no significant differences in bactericidal effects were found. Furthermore, in the year 2008 by Aiello et al. [8] 
and also in the year 2015 by Kim et al. [3] supported the idea that antibacterial soaps are not so significant compared to bland soaps. Added antibacterial agents have very little time to show bactericidal action; therefore, the mechanical aspect of friction is of critical importance. In the food and health care industries, hand-washing practices matter the most. The activity of soap, friction, and rinsing are crucial for effective antibacterial action $[9,10]$.

Not all bacteria are pathogenic, and bactericides are not required to be used on daily usable products. Antibacterial agents are used in many personal care products such as soaps, toothpaste, lotions, shampoos, and other household products such as kitchenware, clothing, furniture, and toys. Irresponsible and abusive use of antimicrobial products is closing the antibiotic era. There have been many outbreaks of foodborne diseases and nosocomial infections due to hand contamination. Ogba et al. [1] reported S. aureus followed by $E$. coli to be the most common isolates on the hands of primary school children in Nigeria. S. aureus and E. coli are associated with skin infections and food poisoning, respectively [11].

Nepal being rich in flora and diversity, a lot of amazing life forms are planted here. Traditionally, plant extracts are used for many purposes including food preservation, flavor enhancement, health improvement, and more. Plant oils are old tested and reliable sources for the treatment of various skin diseases and are therefore used in body and skincare products [12]. Plant-derived compounds represent an unlimited source of safe, effective, and environmentally friendly antimicrobials. Due to the fascinating antimicrobial effects, nontoxic nature, and low cost, many self-care products like lotions, toothpaste, soaps, etc., manufactured here have been enriched with the extracts of natural products [13]. The herbal-based cosmetics are rich in phytochemicals such as vitamins, proteins, tannins, terpenoids, and other bioactive ingredients that possess antioxidant, anticancer, antimicrobial, and other beneficial actions [14]. Low toxicity to users and the environment provides a great deal of beauty and medicinal effects [15]. Of the five soaps selected, two (OKT and NM) contained only herbal products, while LX and LRL contained plant extracts added with chemicals.

The present paper aims to evaluate some solution behavior and in vitro antibacterial efficacy of five toilet soap formulations containing both herbal and chemical-based ingredients. The soap contains surfactants that lower the surface tension of the solution. Lower surface tension has taken advantage of improved cleansing action by easy diffusion on the skin surface [16]. With the increase in the purity of soap, there is a profound effect in the electrical conductivity, and the presence of impurities can cause some constraints on the mobility of charge of the soap solution $[17,18]$. Most plant extracts used in herbal-based soaps have medicinal value. In addition, the antibacterial efficacy of natural herbal extracts in soap was compared and evaluated.

\section{Experimental}

2.1. Materials and Methods. All chemicals and reagents used for this experiment were of analytical reagent grade. Five soaps were selected for assessment and were purchased from the local market of Biratnagar, Nepal. These soap formulations are coded as Lux (LX), Lifebuoy (LFBY), Liril (LRL), Okhati (OKT), and Chiuree Neem (NM). Their ingredients are listed in Table S1. A Kruss K20S Easy Dyne Force Tensiometer was employed to measure the surface tension by the ring detachment technique using a platinum ring with the correction of Harkins and Jordan. The Autoranging Conductivity/TDS meter TCM 15+ was used to measure the specific conductance of soap solutions. For the antibacterial efficacy assessment, the glassware was washed with triple distilled water and dried in the oven before use. Pyrogen-free distilled water was used for the preparation of solutions and was made at their four different concentrations such as $1: 01$, $1: 02,1: 04$, and $1: 08$. To explore the solution properties, all soaps solutions were prepared at $0.2 \mathrm{mg} / \mathrm{mL}$ concentration and kept as stock solutions. Further, the internal dilution in tap water was preformed 15 times for all. This study, carried in tap water, was to mimic the daily household procedure.

2.2. Antimicrobial Assay. The antibacterial sensitivity of the soap was studied by the disc diffusion technique. Three different bacterial pathogens: E. coli, S. Aureus, and $P$. vulgaris, which are known to reside on the body surface and give evidence to cause piles of diseases, are deployed in this evaluation. The bacterial culture was revived by seeding some well-isolated colonies of pathogens in nutrient broth and incubated for two hours. The sterile Mueller-Hinton agar solution prepared by standard technique was left to congeal in the sterile Petri plates. The broth of previously seeded bacterial culture was spread in the media and the well-sterilized paper discs of $5 \mathrm{~mm}$ diameter (Whatman no. 1) impregnated with test samples were stuck on the plates. For comparison of efficacy, a disc of antibiotic (amikacin, $30 \mu \mathrm{g} /$ disc), was also installed. The plates were incubated at $37^{\circ} \mathrm{C}$ for 24 hours. The antibacterial sensitivity was then assessed by measuring the diameter of the zone of inhibition in $\mathrm{mm}$. All the procedures were repeated three times to reduce errors.

\section{Results and Discussion}

3.1. Conductivity and Thermodynamic Properties. The specific conductance of surfactants depends on the nature of ions formed after ionization, the nature of the solvent used, the temperature, and the presence of additives like salts [19]. The variation of specific conductivity with the concentration of soap is well demonstrated in Table 1 and Figure 1. LX has the lowest specific conductivity $(0.404 \mathrm{mS} / \mathrm{cm})$ while LFBY $(0.454 \mathrm{mS} / \mathrm{cm})$ has the highest. The decrease in specific conductivity with dilution is due to the replacement of ions by colloidal particles, which, although conducting, has a lower equivalent conductivity than the ions from which they are formed. Colloidal particles are thus formed in very low concentrations [20]. Upon dilution, the specific conductivity of all soaps has significantly reduced. On the overall view, we can take the specific conductivity of LFBY, NM, and OKT as higher values and LRL and LX as lower values. 
TABle 1: Concentration against specific conductivity of different soap samples.

\begin{tabular}{lcccccc}
\hline \multicolumn{7}{c}{ Conductivity $(\mathrm{mS} / \mathrm{cm})$} \\
S. & $\begin{array}{c}\text { Concentration } \\
(\mathrm{mg} / \mathrm{mL})\end{array}$ & OKT & NM & LFBY & LRL & LX \\
$\mathrm{N}$ & 0.200 & 0.441 & 0.448 & 0.459 & 0.429 & 0.400 \\
\hline 1 & 0.166 & 0.434 & 0.443 & 0.454 & 0.421 & 0.393 \\
2 & 0.143 & 0.430 & 0.438 & 0.449 & 0.416 & 0.386 \\
3 & 0.125 & 0.425 & 0.435 & 0.445 & 0.412 & 0.380 \\
4 & 0.111 & 0.423 & 0.433 & 0.444 & 0.409 & 0.378 \\
5 & 0.100 & 0.419 & 0.428 & 0.441 & 0.407 & 0.372 \\
6 & 0.090 & 0.417 & 0.425 & 0.438 & 0.402 & 0.367 \\
7 & 0.083 & 0.413 & 0.424 & 0.436 & 0.398 & 0.363 \\
8 & 0.076 & 0.409 & 0.423 & 0.435 & 0.392 & 0.357 \\
9 & 0.071 & 0.403 & 0.419 & 0.433 & 0.387 & 0.355 \\
10 & 0.066 & 0.398 & 0.416 & 0.432 & 0.385 & 0.352 \\
11 & 0.062 & 0.395 & 0.413 & 0.430 & 0.384 & 0.348 \\
12 & 0.058 & 0.391 & 0.409 & 0.427 & 0.382 & 0.345 \\
13 & 0.055 & 0.388 & 0.405 & 0.425 & 0.380 & 0.343 \\
14 & 0.052 & 0.385 & 0.401 & 0.421 & 0.376 & 0.341 \\
15 & 0.05 & 0.382 & 0.399 & 0.418 & 0.375 & 0.339 \\
16 & Tap water & & & 0.383 & & \\
17 & & & & & & \\
\hline
\end{tabular}

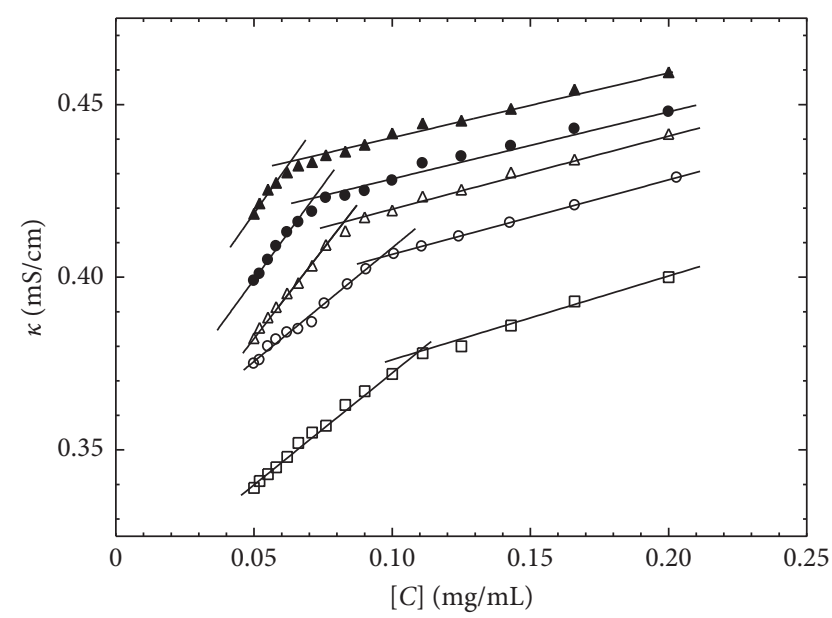

FIgURE 1: Graph depicting the variation of specific conductance with the concentration of different soaps: LFBY (closed triangles), NM (closed circles), OKT (triangles), LRL (circles), and LX (squares).

3.2. Critical Micelle Concentration. The specific conductance of soaps in water for the calculation of the CMC at $303.15 \mathrm{~K}$ is shown in Figure 1. The specific conductivity increases with the increase of concentration with a certain slope. But at a particular concentration, the slope changes. The breaking point of two linear variations is called critical micelle concentration (CMC). A degree of dissociation $(\alpha)$ is obtained from the ratio of postmicellar $\left(S_{2}\right)$ to the premicellar slope $\left(S_{1}\right)$. The variations in the pre- and postmicellar slopes on the plots of specific conductance with a concentration of the solution of soaps are given in Table 2 .

3.3. Correlation of $\left(\kappa_{o} / \kappa_{C M C}\right)$ with Soaps. In the year 2012, Mukhim and Ismail [21] proposed the ratio of the solvent surface tension to the limiting surface tension at the $\mathrm{CMC}$, $\left(\gamma_{o} / \gamma_{\mathrm{CMC}}\right)$, to describe the solvophobic effect [22]. But here we tried to see the ratio of solvent conductance to the conductance at the CMC with soaps. Figure 2 shows the variation in the ratio of the solvent conductance to the conductance at the CMC with soaps. The fitting is from the polynomial equations having correlation coefficients, $r^{2}=1$. The highest ratio value is for $\mathrm{LX}(5)$, whereas the least ratio value is for LFBY (1). The concave curve of $\left(\kappa_{o} / \kappa_{\mathrm{CMC}}\right)$ with soaps is observed (Figure 2). Hence, the higher the ratio values of $\left(\kappa_{o} / \kappa_{\mathrm{CMC}}\right)$, the better the cleansing action.

We used the variation of X-axis of soaps as LFBY (1), NM (2), OKT (3), LRL (4), and LX (5).

3.4. Correlation of Slopes with Soaps. The premicellar slope $\left(S_{1}\right)$ sharply decreases with LFBY, NM, OKT, LRL, and LX. The fitting of the data was done by the polynomial equation with the correlation coefficient, $r^{2}=1$. The postmicellar slope $\left(S_{2}\right)$ increases monotonously with LFBY, NM, OKT, LRL, and LX. The fitting of the data was done in the quadratic equation with the correlation coefficient, $r^{2}=1$, but it looks like linear variation (Figure 3).

All soaps have shown the highest pre-CMC slopes and the lowest post-CMC slopes leading to the lowest degrees of dissociation (Table 2). These slopes are so sensitive that they determine the degrees of dissociation, CMC, and other thermodynamic parameters. The CMC obtained for all soaps from conductivity measurements in water at $303.15 \mathrm{~K}$ is given in Table 2. It indicates that CMC increases with LFBY, NM, OKT, LRL, and LX. The increase of CMC and a within the ascending order of LFBY, NM, OKT, LRL, and LX in the aqueous medium is shown in Table 2. The reason for the highest CMC on LX is due to the presence of the huge numbers of ingredients that slow down the dielectric constant of water, and hence CMC increases. Such an increase of CMC with the decrease of the dielectric constant of water in the presence of external compounds was also found in the literature [23]. It is well known that the presence of various compounds diminishes aggregation number of the micelles which then causes an increment in the electrostatic repulsion between the cationic head group of LX and leads to a reduction in the electrical charge density at the micellar surface. This may be the reason for the increase in $\alpha$ [24].

CMC increases sharply with ascending order of LFBY, NM, OKT, LRL, and LX (Figure 4). The nature of the curve looks like somehow linear but concave fitting by the polynomial equation of correlation coefficient, $r^{2}=1$.

The increases sharply with ascending order of LFBY, NM, OKT, LRL, and LX (Figure 5). The nature of the curve looks like concave fitting by the polynomial equation of the correlation coefficient, $r^{2}=1$.

The free energies of micelle formation of soaps are calculated by a pseudophase separation model [23] and the data are given in Table 2:

$$
\Delta G_{\mathrm{m}}^{o}=(2-\alpha) R T \ln X_{\mathrm{CMC}},
$$

where $X_{\mathrm{CMC}}, R$, and $T$ have usual meanings.

$\Delta G_{\mathrm{m}}^{o}$ is negative with all soaps and becomes less negative from the ascending order of LFBY, NM, OKT, LRL, and LX 
TABLE 2: Values of premicellar slope $\left(S_{1}\right)$, postmicellar slope $\left(S_{2}\right)$, degree of dissociation $(\alpha)$, critical micelle concentration (CMC), and Gibbs free energy of micellization $\left(\Delta G_{\mathrm{m}}^{o}\right)$ of LFBY, NM, OKT, LRL, and LX in aqueous medium at $303.15 \mathrm{~K}$.

\begin{tabular}{lccccc}
\hline Soaps & $\mathrm{S}_{1}\left(\mathrm{mS} \mathrm{cm}^{-1} \mathrm{ml} \cdot \mathrm{mg}^{-1}\right)$ & $\mathrm{S}_{2}\left(\mathrm{mS} \mathrm{cm}^{-1} \mathrm{ml} \cdot \mathrm{mg}^{-1}\right)$ & $\alpha$ & \left.${\mathrm{CMC}\left(\mathrm{mg}^{-1}\right)}_{\left.\mathrm{mL}^{-1}\right)} G_{m}^{o}(\mathrm{kJmol})^{-1}\right)$ \\
\hline LFBY (1) & 1.14 & 0.187 & 0.164 & 0.06295 & -31.37 \\
NM (2) & 1.10 & 0.194 & 0.176 & 0.07174 & -30.57 \\
OKT (3) & 1.04 & 0.211 & 0.203 & 0.08323 & -29.93 \\
LRL (4) & 0.658 & 0.216 & 0.328 & 0.09502 & -27.28 \\
LX (5) & 0.647 & 0.243 & 0.376 & 0.1089 & -25.93 \\
\hline
\end{tabular}

The error limits of $\alpha, \mathrm{CMC}$, and $\Delta G_{\mathrm{m}}^{o}$ are within $\pm 4, \pm 4$, and $\pm 5 \%$, respectively.

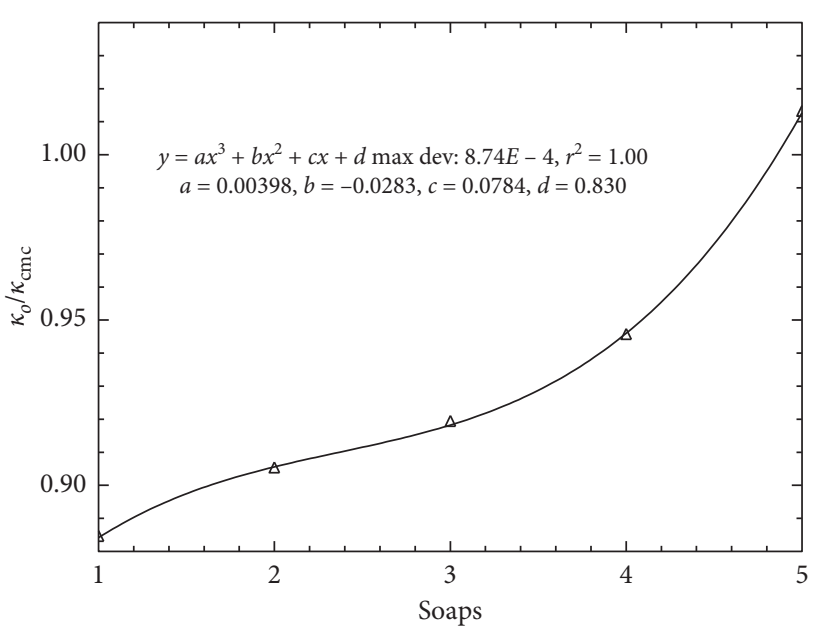

Figure 2: Variation of $\left(\kappa_{o} / \kappa_{\mathrm{CMC}}\right)$ with different soaps: LFBY $(1)$, NM (2), OKT (3), LRL (4), and LX (5).

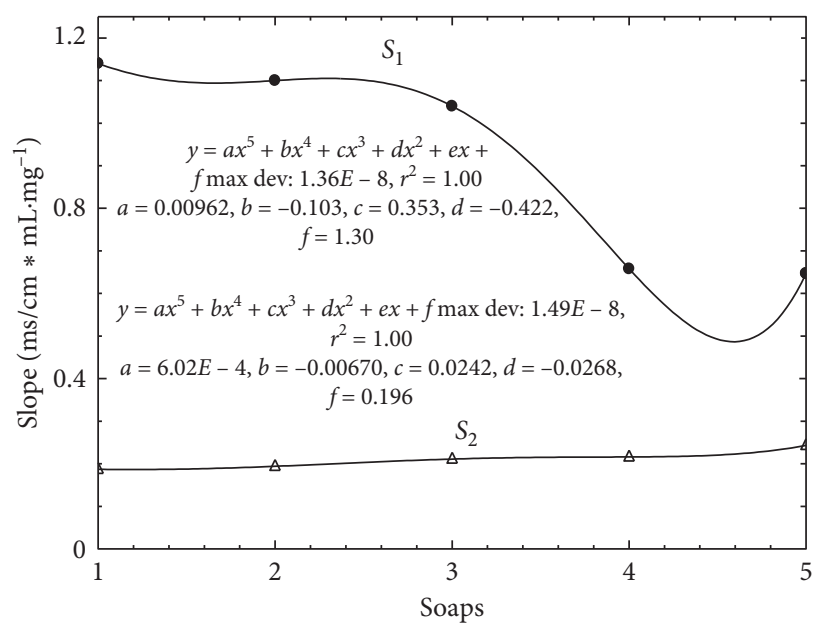

FIGURE 3: Variation of slope versus soaps in premicellar slope $\left(S_{1}\right)$ and postmicellar slope $\left(S_{2}\right)$ regions.

(Table 2). The nature of the curve looks like concave fitting by the polynomial equation of correlation coefficient, $r^{2}=1$ (Figure 6). The higher negative $\Delta G_{\mathrm{m}}^{o}$ indicates that the micellization process is spontaneous and becomes less spontaneous from the ascending order of LFBY, NM, OKT, LRL, and LX (Table 2). Less negative $\Delta G_{\mathrm{m}}^{o}$ indicates co-solute does not facilitate the micellization [25].

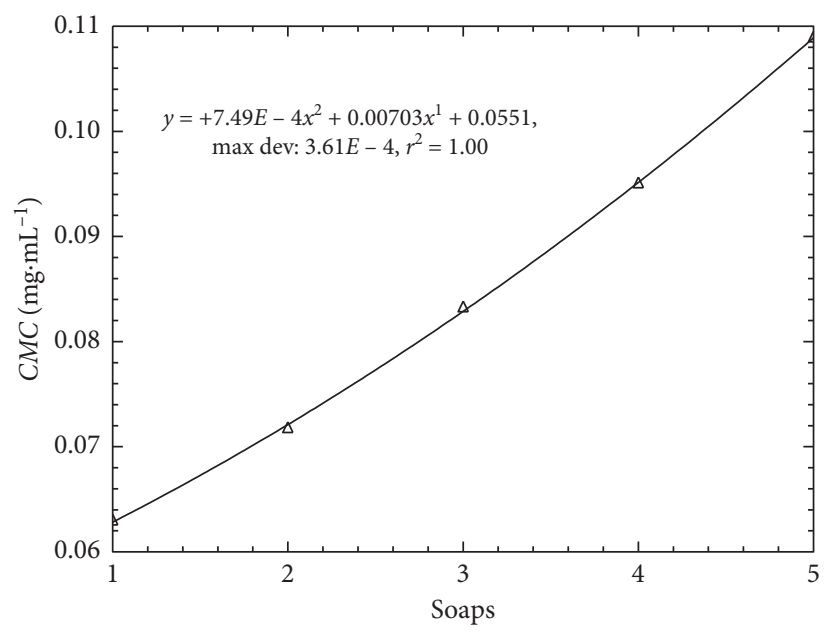

FIGURE 4: Variation of CMC versus soaps.

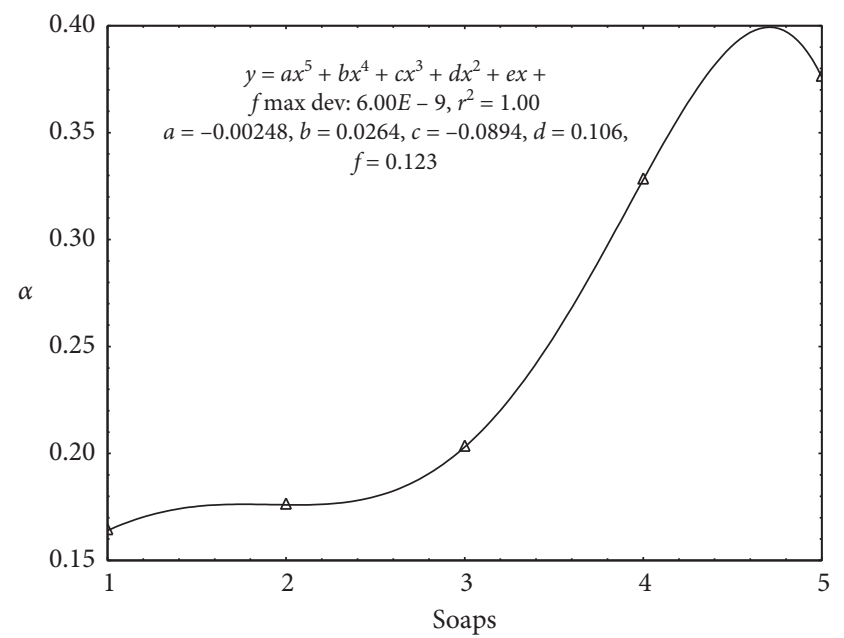

FIgURE 5: Variation of $\alpha$ versus soaps.

3.5. Model for Critical Micelle Concentration. We are very familiar with the CMC determination from the intersection of the two straight lines drawn before and after the break in the $K$ against soap concentration (c) plot (Figure 7). Here, we have also used the concept of Carpena et al. [26] for our data of soaps. Let us take the derivative of the sigmoid type and can be described by using a Boltzmann-type sigmoid that has the following equation: 


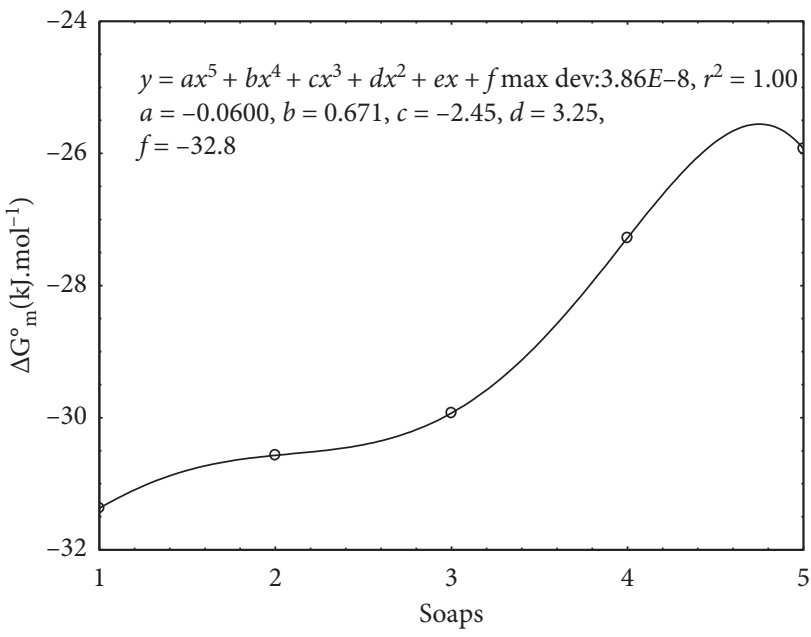

Figure 6: Variation of $\Delta G_{\mathrm{m}}^{o}$ versus soaps.

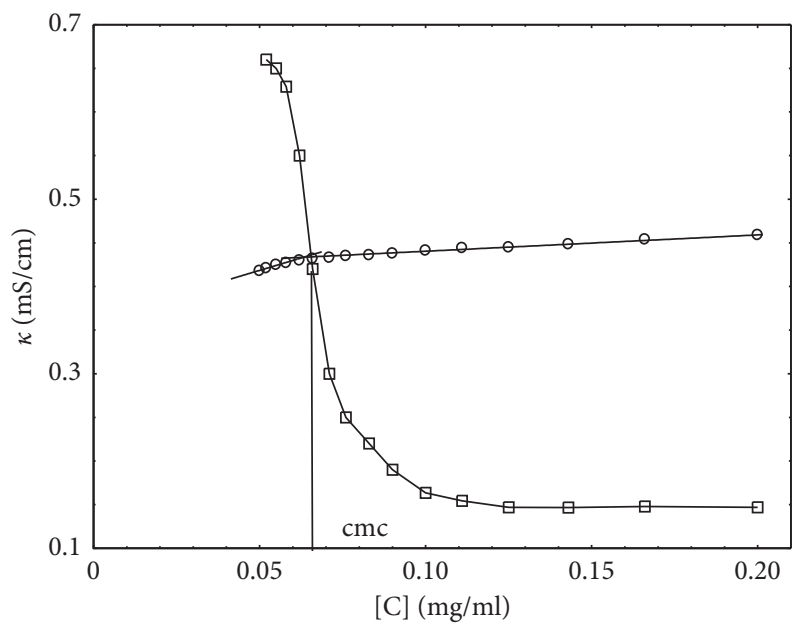

FIgURE 7: Experimental data of conductivity (circles) against concentration, the break point of two straight lines is the CMC; $K_{(c)}$, and their corresponding first derivative (squares), $\kappa_{(c)}$, for LFBY at $303.15 \mathrm{~K}$. The lines are the best fits of data.

$$
\kappa_{(c)}=\frac{A_{1}-A_{2}}{1+e^{\left(c-c_{o / \Delta c}\right)}}+A_{2} .
$$

On integrating equation (2), we get

$$
K_{(c)}=K_{(0)}+A_{1} c+\Delta c\left(A_{2}-A_{1}\right) \ln \left(\frac{1+e^{\left(c-c_{o / \Delta c}\right)}}{1+e^{\left(-c_{o / \Delta c}\right)}}\right),
$$

where $K_{0}, A_{1}, A_{2}$, and $\Delta c$ are the specific conductivity of the solution at zero concentration of the soap, premicellar slope, postmicellar slope, and width of the transition, respectively. This is one of the most efficient methods, which is being used recently, especially for the micellization of soap where probably a weak curvature is obtained. The central point on the width of the transition $\left(c_{o}\right)$ corresponds to CMC, and the degree of counterion dissociation $(\alpha)$ can be determined from the ratio of the postmicellar slope to the premicellar slope as $\alpha=A_{2} / A_{1}$ [23].
A smaller value of $\Delta c$ means abrupt transition (micellization is highly cooperative), while its higher value shows a gradual transition (micellization process is less cooperative). In the analysis, $K_{(0)}$ was set equal to zero because the conductivity of the solvent was substracted corresponding to each data point. Data fitting was carried out by making use of initial guess values of $A_{1}, A_{2}, c_{o}$, and $\Delta c$ in equation (3) to calculate an approximate value of conductivity, $K_{c}^{\text {approx }}$, corresponding to each surfactant concentration. Chi-square, $\chi^{2}$, the sum of the squares of deviations of approximate conductivity from the experimental values, is defined as

$$
\chi^{2}=\sum_{i=1}^{N}\left[K_{i}-K_{i}^{\mathrm{approx}}\right]^{2}
$$

(where $N$ is the number of data points and $K_{i}$ and $K_{i}^{\text {approx }}$ are the experimental conductivity and approximate conductivity at a given soap concentration, respectively) was minimized with respect to these parameters and their values corresponding to the minimum were then used as the new set of guess values in an iterative procedure till $\chi^{2}$ effectively stopped decreasing, indicating convergence of input and output parameters. The minimized value of $\chi^{2}$ gives maximum likelihood estimate of model parameters. Equation (3) being nonlinear in the parameters, a computer program for the nonlinear least-squares fitting of data, as described by Press et al. [27] and making use of the Levenberg-Marquardt algorithm, was written with necessary modification to perform the iterative procedure for the optimization of parameters. The final set of values $K_{0}, A_{1}, A_{2}$, and $\Delta c$ when $\chi^{2}$ effectively stopped decreasing was taken as their best-fit parameters. Figure 7 shows the representative conductivity concentration plot of LFBY in water at $303.15 \mathrm{~K}$.

The CMC obtained from the conventional procedure is $0.06295 \mathrm{mg} / \mathrm{ml}$, whereas CMC from the first derivative is $0.064 \mathrm{mg} / \mathrm{ml}$ (equation 2) and the CMC from the integral equation (3) is $0.0625 \mathrm{mg} / \mathrm{ml}$. Micelles only form when the concentration of soap is greater than the CMC. Therefore, the higher the concentration, the more micelles there are. The cleaning action is associated with the CMC. In our study, we have seen that the formation of the micelles is highest for LX. At this point, the LX will have the highest number of micelles to wet the substrate. The cleaning is not effective due to fewer micelle formation in the cleaning solution as it is superconcentrated. Fewer micelles and foaming in the cleaning solution are not beneficial in the cleaning application [28].

3.6. Surface Tension and Surface Properties. Soaps are usually amphiphilic organic compounds that have the ability to change the interfacial properties of liquids in which they are present, even at a very low quantity. The lower the surface tension, higher will be the cleansing action and vice versa [29]. We want to study the micellization behavior of soaps in water at $303.15 \mathrm{~K}$ from the surface tension study. The values of critical micelle concentration (CMC), maximum surface excess concentration $\left(\Gamma_{\max }\right)$, area occupied by per surfactant molecule $\left(A_{\text {min }}\right)$, surface pressure $\left(\pi_{\mathrm{CMC}}\right)$, solution surface 
tension $\left(\gamma_{\mathrm{CMC}}\right)$, solvent surface tension $\left(\gamma_{\mathrm{o}}\right)$, free energies of adsorption $\left(\Delta G_{\text {ads }}^{\mathrm{o}}\right)$, efficiency of adsorption $\left(\mathrm{p} C_{20}\right)$, effective Gibbs free energy $\left(\Delta G_{\text {eff }}^{\text {o }}\right)$, relation between $A_{\min }$ and $\pi_{\mathrm{CMC}}$, the correlation of slope $(\mathrm{d} \gamma / \operatorname{dlog} C),\left(\gamma_{o} / \gamma_{\mathrm{CMC}}\right),\left(\Gamma / \Gamma_{\max }\right)$, $\left(\Delta G_{\mathrm{ads}}^{o} / \Delta G_{\mathrm{m}}^{o}\right)$, and $\left(\mathrm{CMC} / p C_{20}\right)$ with soaps are also included in this study. The experimental data of surface tension of soaps are compared with the theoretical model.

As we talk about soaps, we see the existence of a hydrophilic head and a hydrophobic tail. All classes of soaps are mostly used in all areas of the present world because of their unique properties. It is well known that the interaction between the soap molecules and water molecules results in a hydrophilic affinity towards the head whereas the hydrophobic affinity towards the tail. As a result, the molecules are oriented on the surface of the water, tail aligning towards the air. This behavior is very common for all classes of soaps. As we increase the concentration of soap, the interaction between the soap molecules and water molecules also increases and the formation of aggregation takes place. Such aggregates are known as micelles [30]. The micelles play a very important role to make the soap significant in the related fields such as pharmaceutical and textile industries. In the micelles, there is always a balance between hydrophobic and hydrophilic forces [31]. Some factors directly affect the morphological behavior of the micellar system. They are additives, temperature as well as solvent composition [32].

Figure 8 depicts the different initial values of surface tension among different soaps. The surface tension of LX, being $52.9 \mathrm{mN} / \mathrm{m}$, is the least and that of LFBY $(59.6 \mathrm{mN} / \mathrm{m})$ is the highest. At all concentrations, the surface tension of LX is relatively low and highest for LFBY (Table 3). All the soaps have shown a general pattern of regular increment of surface tension upon dilution. Also, we have seen that the surface tension of soap at first decreases with increasing concentration of soap and then follows a sigmoid curve between surface tension $(\gamma)$ and $\log [$ surfactant]. There is a formation of a visible break on the sigmoidal curve after which the surface tension remains approximately constant. The breaking point is called the CMC [33].

Such studies of soaps are scarce but only the surface tension of shampoos is studied [34] without explanation of the micellization behavior of shampoos. Our first aim is to investigate the aggregation behavior of soaps in water at $303.15 \mathrm{~K}$ in detail and the second aim is to compare our experimental data of surface tension of soap with the theoretical model. The surface tension of soap solutions in water was plotted against the concentration to get the $\mathrm{CMC}$ values at $303.15 \mathrm{~K}$. The representative figure (Figure 9) shows the variation of the surface tension of soap in water at $303.15 \mathrm{~K}$.

From the plot of surface tension with the concentration of soap solution, the following surface properties are calculated [35]. The maximum surface excess concentration at the air-water interface $\Gamma_{\max }$ has been calculated by applying Gibbs isotherm:

$$
\Gamma_{\max }=-\frac{1}{2.303 n R T}\left[\frac{\mathrm{d} \gamma}{\operatorname{dlog} C}\right]_{T, P},
$$

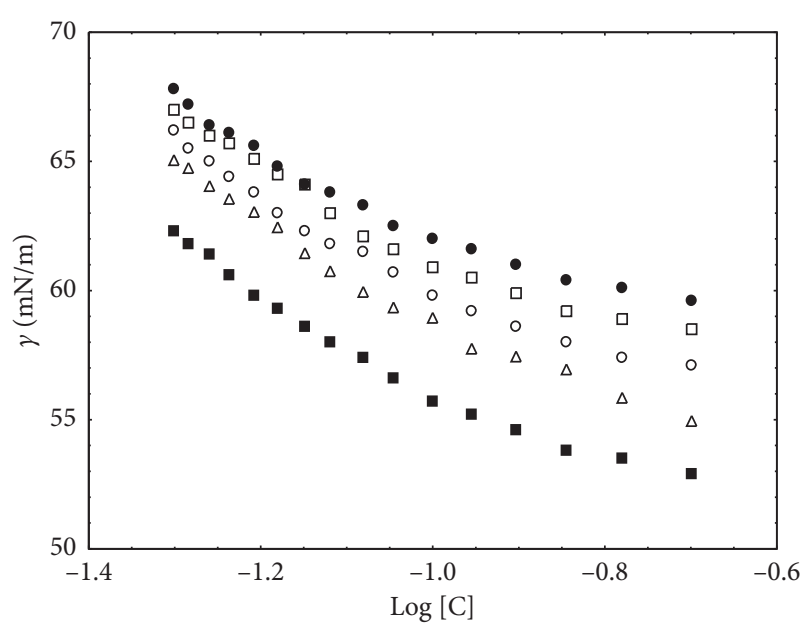

FIGURE 8: Graph representing the dependence of surface tension with the concentration: LFBY (closed circles), NM (squares), OKT (circles), LRL (triangles), and LX (closed squares).

TABLE 3: Concentration versus surface tension of different soap samples.

\begin{tabular}{lcccccc}
\hline \multicolumn{7}{c}{ Surface tension $(\mathrm{mN} / \mathrm{m})$} \\
S. N. & Concentration $(\mathrm{mg} / \mathrm{mL})$ & NM & OKT & LRL & LFBY & LX \\
\hline 1 & 0.200 & 58.5 & 57.1 & 54.9 & 59.6 & 52.9 \\
2 & 0.166 & 58.9 & 57.4 & 55.8 & 60.1 & 53.5 \\
3 & 0.143 & 59.2 & 58.0 & 56.9 & 60.4 & 53.8 \\
4 & 0.125 & 59.9 & 58.6 & 57.4 & 61.0 & 54.6 \\
5 & 0.111 & 60.5 & 59.2 & 57.7 & 61.6 & 55.2 \\
6 & 0.100 & 60.9 & 59.8 & 58.9 & 62.0 & 55.7 \\
7 & 0.090 & 61.6 & 60.7 & 59.3 & 62.5 & 56.6 \\
8 & 0.083 & 62.1 & 61.5 & 59.9 & 63.3 & 57.4 \\
9 & 0.076 & 63.0 & 61.8 & 60.7 & 63.8 & 58.0 \\
10 & 0.071 & 64.1 & 62.3 & 61.4 & 64.1 & 58.6 \\
11 & 0.066 & 64.5 & 63.0 & 62.4 & 64.8 & 59.3 \\
12 & 0.062 & 65.1 & 63.8 & 63.0 & 65.6 & 59.8 \\
13 & 0.058 & 65.7 & 64.4 & 63.5 & 66.1 & 60.6 \\
14 & 0.055 & 66.0 & 65.0 & 64.0 & 66.4 & 61.4 \\
15 & 0.052 & 66.5 & 65.5 & 64.7 & 67.2 & 61.8 \\
16 & 0.050 & 67.0 & 66.2 & 65.0 & 67.8 & 62.3 \\
17 & Tap water & & & 71.34 & & \\
\hline
\end{tabular}

where $\gamma$ denotes the surface tension, $R$ is the gas constant $\left(8.314 \mathrm{~J} \cdot \mathrm{mol}^{-1} \cdot \mathrm{K}^{-1}\right), T$ is the absolute temperature, $C$ is the soap concentration, and $(\mathrm{d} \gamma / \mathrm{d} \log C)$ is the slope of the $\gamma$ versus $\log C$ plot taken at CMC. The constant $n$ takes the values 2 for conventional soap where the soap ion and the center line are univalent. The area occupied per soap molecule $\left(A_{\min }\right)$ at the air-water interface has been obtained by

$$
A_{\min }=\frac{1}{N \Gamma_{\max }},
$$

where $N$ is Avogadro's number.

The value of the surface pressure at the CMC $\left(\pi_{\mathrm{CMC}}\right)$ is obtained as

$$
\pi_{\mathrm{CMC}}=\gamma_{o}-\gamma_{\mathrm{CMC}} \text {, }
$$




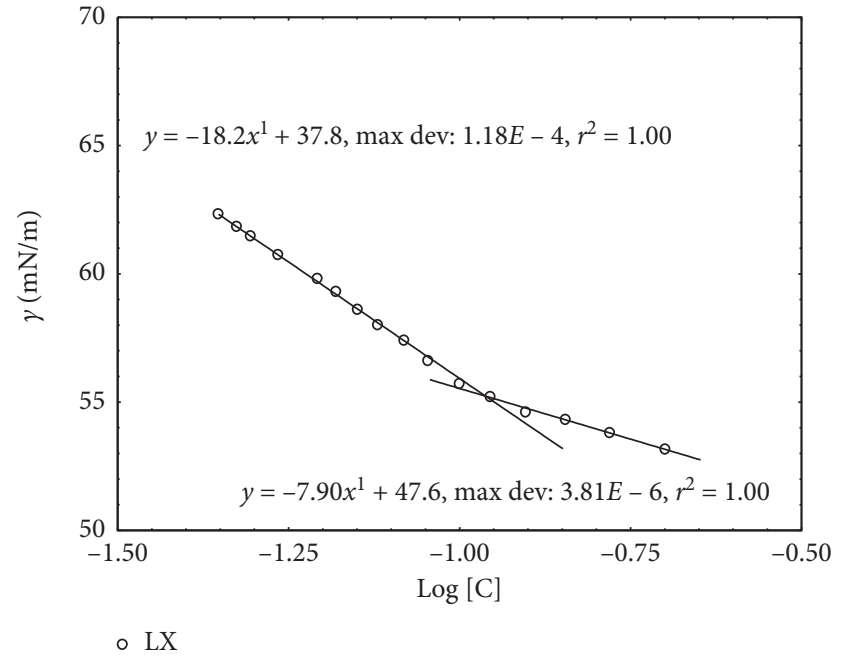

Figure 9: Plot of surface tension versus concentration of a representing soap (LX) solution at $303.15 \mathrm{~K}$.

where $\gamma_{\mathrm{o}}$ and $\gamma_{\mathrm{CMC}}$ are the values of surface tension of water and the soap solution at the $\mathrm{CMC}$, respectively.

The standard free energy interfacial adsorption at the air/ saturated monolayer interface can be evaluated from the relation [36]:

$$
\Delta G_{\mathrm{ads}}^{o}=\Delta G_{\mathrm{m}}^{o}-\frac{\pi_{\mathrm{CMC}}}{\Gamma_{\max }}
$$

$A_{\text {min }}$ refers to the property associated with the soap monolayer at the air/water interface. The maximum surface excess concentration at the air/water interface $\left(\Gamma_{\max }\right)$, area occupied per surfactant molecule $\left(A_{\min }\right)$ at the air-water interface, surface pressure at the CMC $\left(\pi_{\mathrm{CMC}}\right)$, and the standard free energy interfacial adsorption $\left(\Delta G_{\text {ads }}^{\mathrm{o}}\right)$ of soaps solutions in water at $303.15 \mathrm{~K}$ are calculated, respectively, and the values are listed in Table 3.

Chakraborty et al. [37] calculated the CMC (mM) of $\mathrm{CTAB}$ at $25^{\circ} \mathrm{C}$ by $(0.959)$ conductivity and by $(0.883)$ tensiometry. Similarly, our CMC of soaps at $303.15 \mathrm{~K}$ by conductivity and tensiometry almost matched each other. The data suggest that $\Gamma_{\max }$ as well as $\pi_{\mathrm{CMC}}$ values decrease with soaps at $303.15 \mathrm{~K}$, indicating the low population of soap molecules at the interface due to the addition of ingredients. Negative values of $\Delta G_{\text {ads }}^{o}$ indicate that the adsorption of soap molecules on the surface is spontaneous and this phenomenon is more spontaneous than the micellization due to larger negative value than $\Delta G_{\mathrm{m}}^{o}$. The values of $\Delta G_{\mathrm{ads}}^{\mathrm{o}}$ become more negative with soaps at $303.15 \mathrm{~K}$ that shows more spontaneity of adsorption of soap molecules on the surface.

3.7. Variation of the Slope of Surface Tension Curve with Soaps. The slope of the surface tension curve (Figure 10) of soaps solution in water at $303.15 \mathrm{~K}$ gives various information about the surface properties of soaps solution [33]. It is seen that the slopes increase with soaps in the order of LFBY, NM, OKT, LRL, and LX.

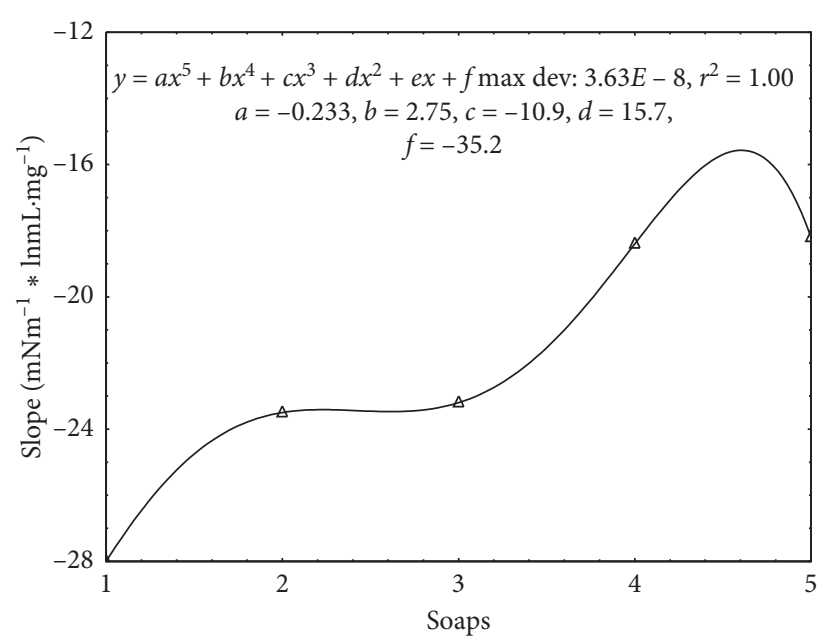

FIgURE 10: Variation of the slope with soap solutions.

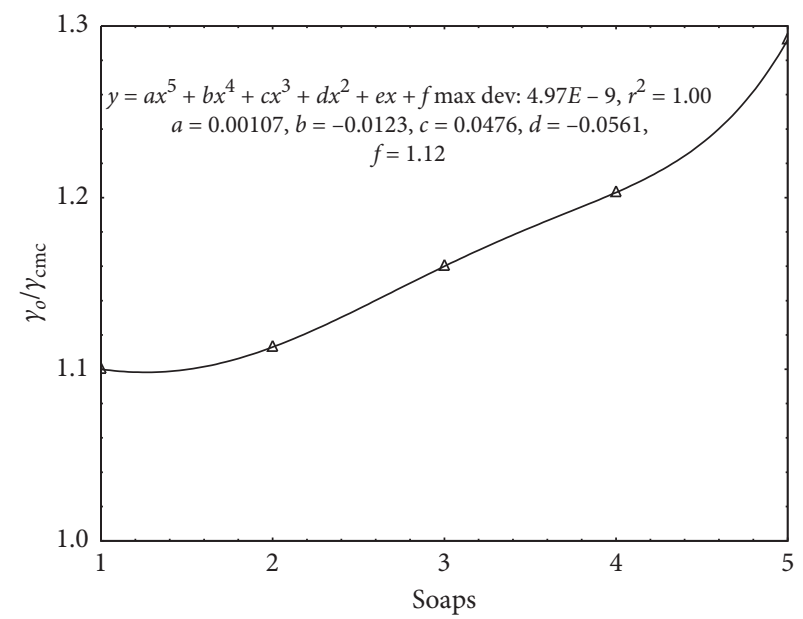

FIGURE 11: Variation of $\left(\gamma_{o} / \gamma_{\mathrm{cmc}}\right)$ with soaps.

3.8. Correlation of $\left(\gamma_{o} / \gamma_{c m c}\right)$ with Soaps. Figure 11 shows the variation of $\left(\gamma_{o} / \gamma_{\mathrm{CMC}}\right)$ with soaps at $303.15 \mathrm{~K}$. The values of $\left(\gamma_{o} / \gamma_{\mathrm{CMC}}\right)$ increase in the order of LFBY, NM, OKT, LRL, and LX. The nature of the curve is concave fitting by the polynomial equation of the correlation coefficient, $r^{2}=1$.

3.9. Correlation of $\Delta G_{a d s}^{o}$ with Soaps. Gibbs energies of adsorption of soaps in water show the unique variation at $303.15 \mathrm{~K}$ (Figure 12). $\Delta G_{\text {ads }}^{o}$ monotonously decreases with soaps in the order of LFBY, NM, OKT, LRL, and LX. The nature of the curve is the combination of convex-concaveconvex fitting by the polynomial equation of correlation coefficient, $r^{2}=1$.

3.10. Correlation of $\Delta G_{\text {eff }}^{o}$ with Soaps. The difference between $\Delta G_{\text {ads }}^{o}$ and $\Delta G_{\mathrm{m}}^{o}$ is called effective Gibbs free energy $\left(\Delta G_{\mathrm{eff}}^{\mathrm{o}}\right)$. The curve of $\Delta G_{\text {eff }}^{o}$ sharply decreases with convex variation by the addition of various soaps in the order of LFBY, NM, OKT, LRL, and LX at $303.15 \mathrm{~K}$ (Figure 13) fitting by the polynomial equation of correlation coefficient, $r^{2}=1$. It is 


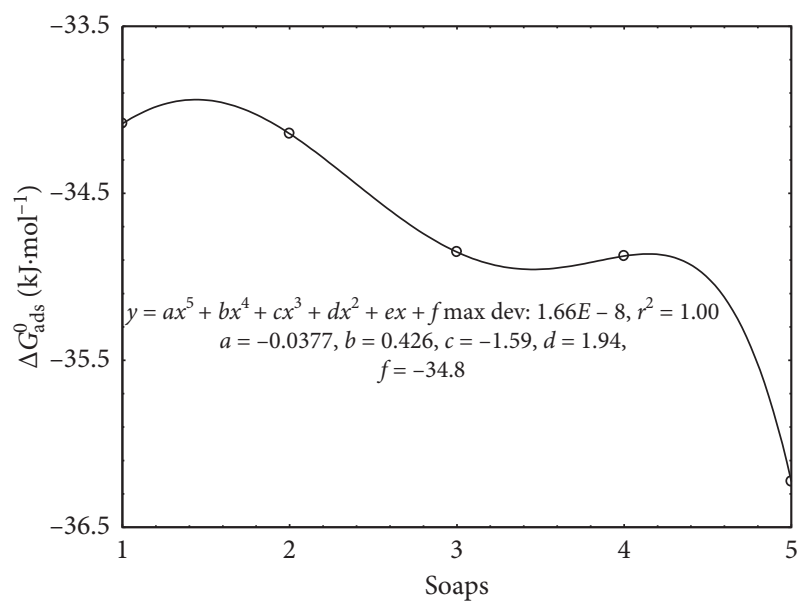

FIGURE 12: Variation of $\Delta G_{\text {ads }}^{o}$ with soaps.

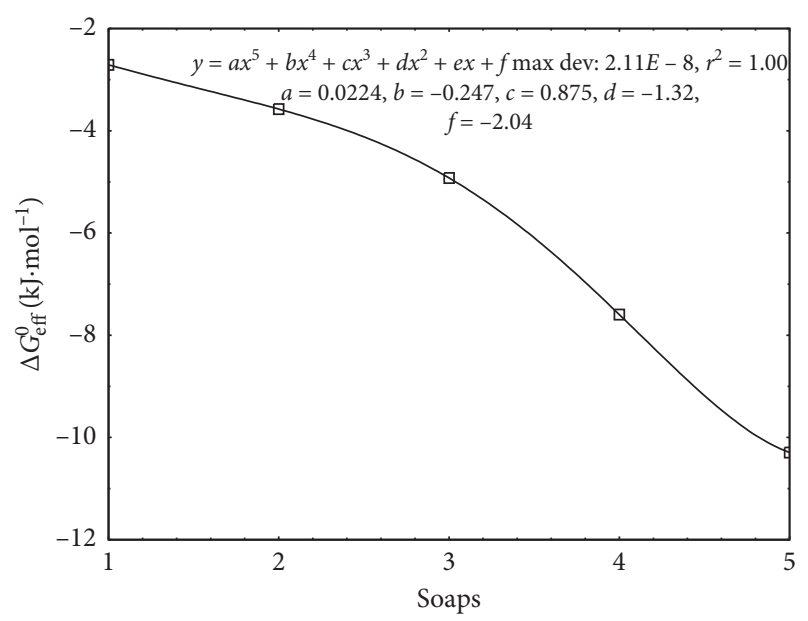

FIGURE 13: Variation of $\Delta G_{\text {eff }}^{o}$ with soaps.

also observed that the values of $\Delta G_{\text {eff }}^{o}$ decrease with an increase in head group polarity of soaps, indicating that aggregation is more favored than the adsorption process, and also less energy is required for the aggregation process [38].

3.11. The Relation between $A_{\min }$ and $\pi_{C M C} \cdot \pi_{\mathrm{CMC}}$ is a measure of the cohesive force in the surfactant film, whereas $A_{\min }$ describes the "orientation" of the surfactant's molecule in an aqueous solution. We also plotted the curve of $\pi_{\mathrm{CMC}} A_{\min }$ with $\pi_{\mathrm{CMC}}$ of LFBY, NM, OKT, LRL, and LX. The nature of the curve at first increases sharply for LFBY and NM and then the curve monotonously increases for OKT and again sharply for LRL. Eventually, the convex curve was seen from LRL to LX at temperature $303.15 \mathrm{~K}$ (Figure 14) fitting by the polynomial equation of correlation coefficient, $r^{2}=1$.

3.12. Correlation of $\left(\Gamma / \Gamma_{\max }\right)$ with Soaps. Applying the Frumkin isotherm equation provided in the literature [39], it was confirmed that the concentration value at which $\gamma$ of water is minimized by $20 \mathrm{mN} / \mathrm{m}$ and the ratio of the Gibbs

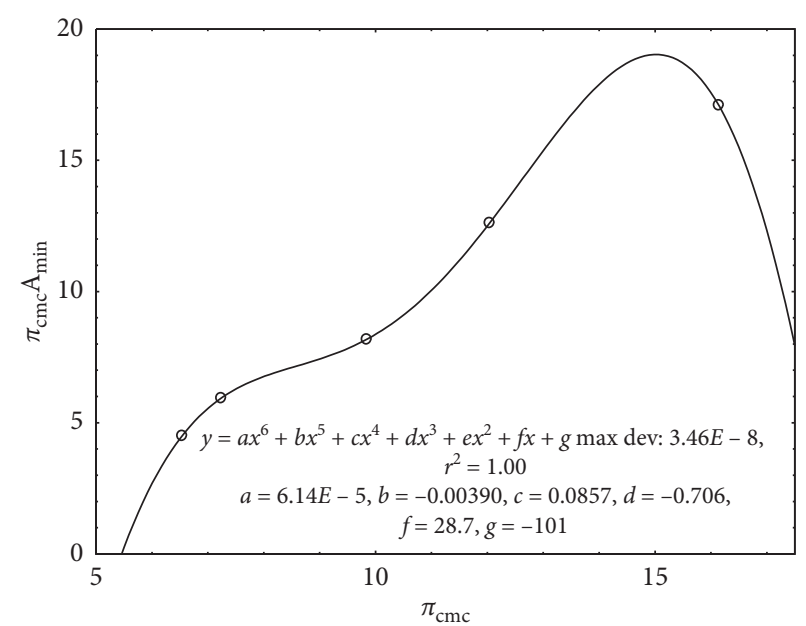

Figure 14: Variation of $\pi_{\mathrm{CMC}} A_{\min }$ with $\pi_{\mathrm{CMC}}$.

surface excess concentration $(\Gamma)$ to the maximal $\left(\Gamma_{\max }\right)$ is within 0.84 to 0.999 .

We have calculated the $\left(\Gamma / \Gamma_{\max }\right)$ values for soaps from the equation used in the literature [39]:

$$
\pi_{\mathrm{cmc}}=-R T \Gamma_{\max } \ln \left(1-\frac{\Gamma}{\Gamma_{\max }}\right) .
$$

Our values of $\left(\Gamma / \Gamma_{\max }\right)$ for soaps perfectly matched within the range of the literature [39].

The values of $\left(\Gamma / \Gamma_{\max }\right)$ increase sharply for soaps in the order of LFBY, NM, OKT, LRL, and LX at $303.15 \mathrm{~K}$ (Figure 15) fitting by the polynomial equation of correlation coefficient, $r^{2}=1$, and finally the curve looks like convex. The highest value of $\left(\Gamma / \Gamma_{\max }\right)$ shown for LX and the lowest for LFBY. But the values of $\left(\Gamma / \Gamma_{\max }\right)$ for all soaps are within the range of 0.66 to 0.99 .

3.13. Correlation of $\left(\Delta G_{a d s}^{o} / \Delta G_{m}^{o}\right)$ with Soaps. The observed $\Delta \mathrm{G}_{\text {ads }}^{\mathrm{o}}$ values are higher than $\Delta \mathrm{G}_{\min }^{\mathrm{o}}$ values, indicating the adsorption at the air-solution interface is more favorable than the formation of micelles in the bulk solution [40]. The ratio of $\left(\Delta G_{\mathrm{ads}}^{o} / \Delta G_{\mathrm{m}}^{o}\right)$ is found in the range of 1.1 to 1.14 for LFBY, $\mathrm{NM}$, OKT, LRL, and LX (Figure 16). The variation of the curve looks concave fitting by the polynomial equation of the correlation coefficient, $r^{2}=0.997$. The value of $\left(\Delta G_{\mathrm{ads}}^{o} / \Delta G_{\mathrm{m}}^{o}\right)$ for LX is the highest and the lowest for LFBY at $303.15 \mathrm{~K}$.

3.14. Correlation of $\left(C M C / p C_{20}\right)$ with Soaps. The ratio of $\mathrm{CMC}$ to $p C_{20}\left(\mathrm{CMC} / p C_{20}\right)$ is an interesting study. Such type of work was observed by Niranjan and Upadhyay in 2010 [41]. The variation of the curve for soaps increases sharply for LFBY, NM, OKT, LRL, and LX (Figure 17) fitting by the polynomial equation of correlation coefficient, $r^{2}=1$. Nature of the curve looks somehow like convex.

3.15. Theoretical Model. The surface tension data for soap solution at $303.15 \mathrm{~K}$ were fitted with a nonlinear least-squares regression analysis using the Szyszkowski equation for the 


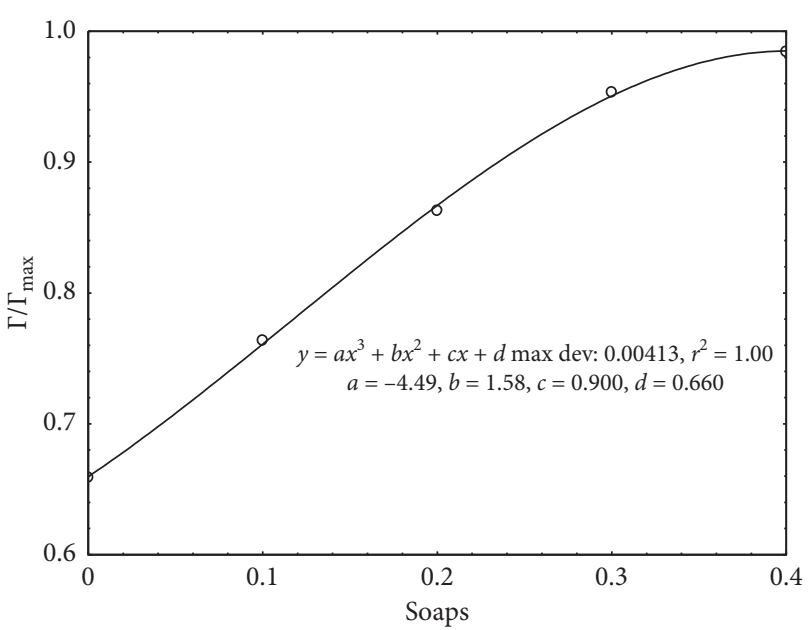

Figure 15: Variation of $\left(\Gamma / \Gamma_{\max }\right)$ with soaps.

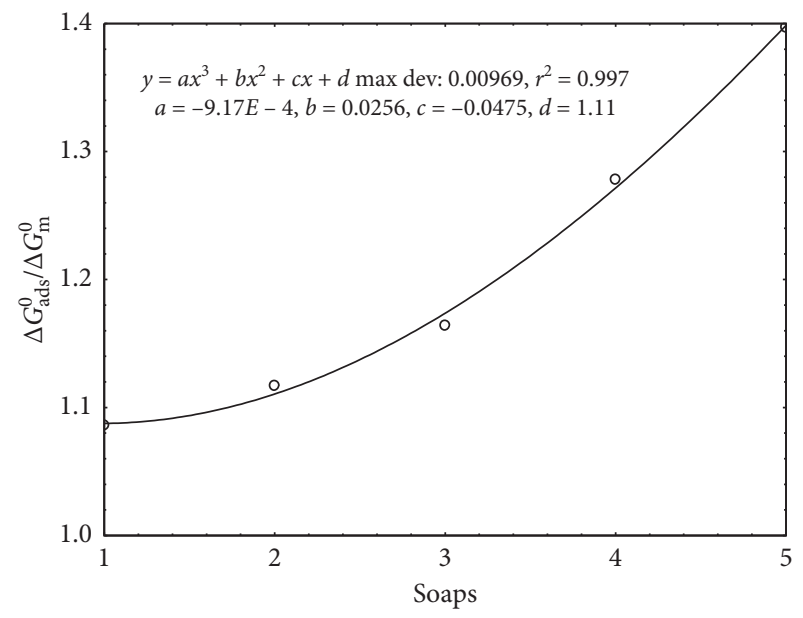

Figure 16: Variation of $\left(\Delta G_{\mathrm{ads}}^{o} / \Delta G_{m}^{o}\right)$ with soaps.

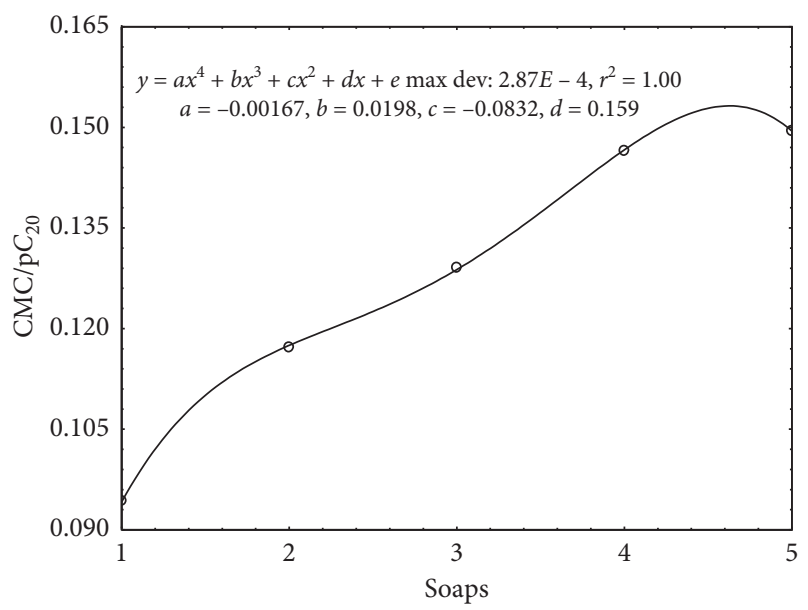

Figure 17: Variation of $\left(\mathrm{CMC} / p C_{20}\right)$ with soaps.

premicellar region, whereas for the postmicellar region, the linear variation was noted. It is also well known that very small concentrations of surface-active impurities affect the transition region around the CMC. By analyzing the surface tension versus concentration data, for the system in the premicellar region is the subject of our interest [42]. Here, soap contains cation and anion. So, we denote the mean ionic activity coefficient of the solution by $\gamma_{ \pm}$, and the following relations can be written by using the Debye-Hückel equation to relate the activity of the surfactant to the ionic strength $(I)$ :

$$
\begin{aligned}
a_{\text {soap }} & =\gamma_{ \pm} C_{\text {anion }_{\text {free }}} \gamma_{ \pm} C_{\text {Cation }_{\text {free }}} \\
I & =[\text { Soap }]_{\text {total }}, \\
\log \left(\gamma_{ \pm}\right) & =\frac{-0.509 I^{0.5}}{\left(1+1.31 I^{0.5}\right)}+0.049 I
\end{aligned}
$$

where $C_{\text {anion }_{\text {free }}}$ and $C_{\text {Cation }_{\text {free }}}$ are molar concentrations of the free anion and cation, respectively. It can be mentioned that the complex formation in the premicellar region does not affect the ionic strength. The combination of the Langmuir model for surface adsorption with the Gibbs equation, $\gamma$, can be explained by the Szyszkowski equation.

$$
\gamma=\gamma_{0}-b \ln \left(1+c a_{\text {soap }}\right)
$$

where $b=\Gamma^{\infty} R T=(R T / \omega), \Gamma^{\infty}$ is the value of surface excess of the soap when a complete monolayer is present, and $\omega$ is the cross-sectional area of the soap molecule at the surface per mole [43]. $c$ is related to the equilibrium constant. By plotting $\gamma$ versus $a_{\text {soap }}$, we get the fitting parameters as $b\left(50.1 \pm 0.30 \mathrm{~m} \cdot \mathrm{Nm}^{-1}\right)$ and $c\left(459 \pm 0.1(\mathrm{mg} / \mathrm{ml})^{-2}\right)$ with correlation coefficient $\left(r^{2}=0.996\right)$ as shown in Figure 18 for LX. It is interesting to see that ongoing from LX to LRL, $\mathrm{OKT}, \mathrm{NM}$, and LFBY, there is an increase of $b$ but the decrease of $c$. The correlation coefficient of the experimental data of all soaps fits around $\left(r^{2}=0.996\right)$ with the model. But we have shown in Figure 18, the more experimental data above the CMC of LRL, OKT, NM, and LFBY to make symmetry in the graph, so we have observed the correlation coefficient of fits look more good to less good (Figure 18) ongoing from LX to LRL, OKT, NM, and LFBY.

The mean square average deviation, $\delta \gamma$, between the experimental (exp) and the predicted model (model) surface tension values is minimized as the relation [44]:

$$
\delta \gamma=\sqrt{\frac{\sum_{i=1}^{N}\left(\gamma_{\exp _{i}}-\gamma_{\text {model }_{i}}\right)^{2}}{N}},
$$

where $N$ is the number of data points. The above model can say "successful" if $\delta \gamma$ is the same as or lower than the estimated error in the surface tension measurements, taken to be within $1 \mathrm{~m} \cdot \mathrm{Nm}^{-1}$ [44]. In our case, $\delta \gamma=0.97 \mathrm{~m} \cdot \mathrm{Nm}^{-1}$. The fit is successful. So, we are also interested to see the minimal value of the surface tension of aqueous solution of soap at $303.15 \mathrm{~K}$ with the help of the equation described elsewhere [45]:

$$
\frac{\Gamma_{\max }}{\Gamma^{\infty} \gamma_{\mathrm{CMC}}}+\left(1-\frac{\Gamma_{\max }}{\Gamma^{\infty}}\right) \gamma_{\mathrm{water}}=\gamma_{\mathrm{cal}}
$$

where $\Gamma_{\max }=0.00156 \quad$ (Table 4), $\quad \Gamma^{\infty}=0.019877$ as $b=\Gamma^{\infty} R T, \gamma_{\mathrm{CMC}}=55.2$ for LX, and $\gamma_{\text {water }}=71.34$, and then the value of $\gamma_{\text {cal }}$ turns out to be $65.74 \mathrm{~m} \cdot \mathrm{Nm}^{-1}$. This is somehow higher than the measured one $\left(55.2 \mathrm{~m} \cdot \mathrm{Nm}^{-1}\right)$. 


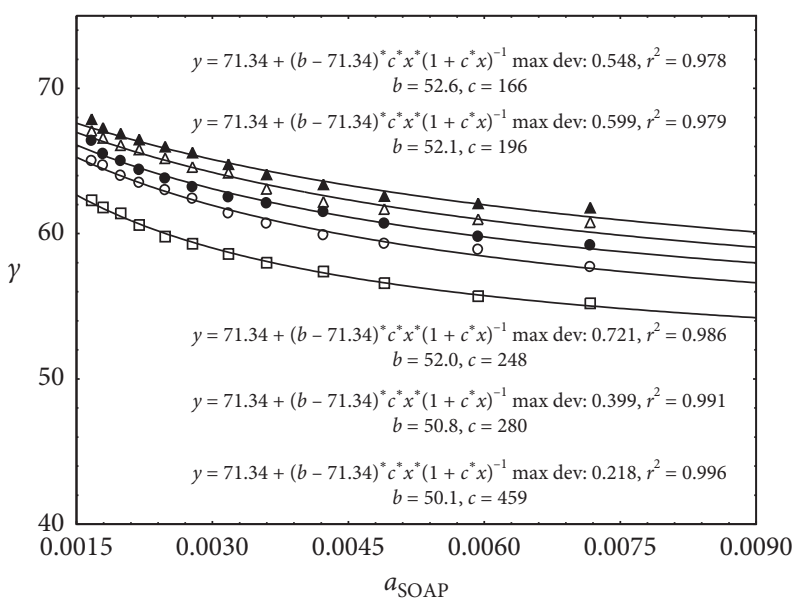

FiguRE 18: Variation of $\gamma$ with $a_{\text {soap }}$ : closed triangles (LFBY), triangles (NM), closed circles (OKT), circles (LRL), and squares (LX); solid lines represent the model.

TABLE 4: Slopes, critical micelle concentration (CMC), maximum surface excess concentration $\left(\Gamma_{\max }\right)$, the area occupied by surfactant molecule $\left(A_{\mathrm{min}}\right)$, surface pressure at the CMC $\left(\pi_{\mathrm{CMC}}\right)$, effective Gibbs free energy $\left(\Delta G_{\text {eff }}^{o}\right)$, and free energy of adsorption $\left(\Delta G_{\text {ads }}^{o}\right)$.

\begin{tabular}{lccccccc}
\hline Soaps & Slopes & $\mathrm{CMC}(\mathrm{mg} / \mathrm{ml})$ & $\Gamma_{\max } 10^{6}\left(\mathrm{~mol} \mathrm{~m}^{-2}\right)$ & $A_{\min }\left(\AA^{2} \mathrm{molecule}^{-1}\right)$ & $\pi_{\mathrm{CMC}}\left(\mathrm{m} \mathrm{Nm}^{-1}\right)$ & $\Delta G_{\mathrm{eff}}^{o}\left(\mathrm{kJmol}^{-1}\right)$ & $\Delta G_{\mathrm{ads}}^{o}(\mathrm{kJmol}$ \\
\hline LFBY & -28.0 & 0.0659 & 2.41 & 68.84 & 6.54 & -2.71 & -34.08 \\
NM & -23.5 & 0.0710 & 2.02 & 82.03 & 7.24 & -3.57 & -34.14 \\
OKT & -23.2 & 0.0830 & 1.99 & 83.43 & 9.84 & -4.92 & -34.85 \\
LRL & -18.4 & 0.0899 & 1.58 & 104.7 & 12.04 & -7.59 & -34.88 \\
LX & -18.2 & 0.1110 & 1.57 & 105.9 & 16.14 & -10.29 & -36.22 \\
\hline
\end{tabular}

The error limits of CMC, $\Gamma_{\max }, A_{\min }, \pi_{\mathrm{CMC}}, \Delta G_{\text {eff }}^{o}$, and $\Delta G_{\text {ads }}^{o}$ are within $\pm 3, \pm 5, \pm 4, \pm 3, \pm 4$, and $\pm 6 \%$, respectively.

Based on Van Oss concept [46], $\gamma$ of water changes in the range of soap concentration in the bulk phase corresponding to the saturated monolayer at the water-air interface. According to this concept $30 \%$ of $\gamma$ of water results from the Lifshitz-Vander Waals and 70\% from the hydrogen bond intermolecular interaction. It may be possible that the involvement of soap molecules in the surface layer causes partial breaking of hydrogen bonds which lowers $\gamma$ of water.

Using the value of $c$, the standard Gibbs energy of adsorption can be calculated as [47]

$$
\Delta G_{\mathrm{ads}}^{o}=-R T \ln (c),
$$

where $R=8.314 \mathrm{~J} \cdot \mathrm{mol}^{-1} \cdot \mathrm{K}^{-1}$ is the gas constant and $T=303.15 \mathrm{~K}$. The value of $\Delta G_{\text {ads }}^{o}$ is equal to $-15.45 \mathrm{~kJ} \cdot \mathrm{mol}^{-1}$ for LX. We are interested to compare the standard Gibbs energy of adsorption for LX at $303.15 \mathrm{~K}$ with the various equations.

Let us take the equation which has the degree of dissociation $(\alpha)$, critical micelle concentration (CMC), and area occupied by per surfactant molecule $\left(A_{\min }\right)$ and surface pressure $\left(\pi_{\mathrm{CMC}}\right)[48]$.

$$
\Delta G_{\mathrm{ads}}^{o}=2.303(2-\alpha) R T \log \mathrm{CMC}-0.6023 \pi_{\mathrm{CMC}} A_{\min } .
$$

Here $\alpha=0.376$ from Table 3 of LX in water at $303.15 \mathrm{~K}$ by conductivity methods and the rest values of $A_{\min }$ and $\pi_{\mathrm{CMC}}$ was taken from Table 4 , then the value of $\Delta G_{\text {ads }}^{o}$ becomes $-10.0288 \mathrm{~kJ} \cdot \mathrm{mol}^{-1}$. From the above discussion, we observe a minimum in the surface tension concentration curve for an
TABLE 5: The diameter of zone of inhibition of the pastes against three pathogenic bacteria.

\begin{tabular}{lccccccccccccc}
\hline Soap & \multicolumn{10}{c}{ The diameter of zone of inhibition in mm } \\
& \multicolumn{3}{c}{ S. aureus } & \multicolumn{1}{c}{ E. coli } & \multicolumn{3}{c}{ P. vulgaris } \\
\hline $\begin{array}{l}\text { Conc } c_{\mathrm{n}} \\
(\mu \mathrm{g} / \mu \mathrm{l})\end{array}$ & 100 & 50 & 25 & 12.5 & 100 & 50 & 25 & 12.5 & 100 & 50 & 25 & 12.5 \\
$\mathrm{OKT}$ & 14 & 15 & 13 & 0 & 0 & 0 & 0 & 0 & 0 & 0 & 0 & 0 \\
$\mathrm{NM}$ & 13 & 19 & 18 & 11 & 0 & 0 & 0 & 0 & 0 & 0 & 0 & 0 \\
$\mathrm{LFBY}$ & 13 & 25 & 20 & 20 & 0 & 0 & 0 & 0 & 8 & 0 & 0 & 0 \\
$\mathrm{LX}$ & 13 & 21 & 25 & 15 & 0 & 0 & 0 & 0 & 0 & 0 & 0 & 0 \\
LRL & 13 & 23 & 17 & 8 & 0 & 0 & 0 & 0 & 0 & 0 & 0 & 0 \\
\hline
\end{tabular}

aqueous solution of LX, and it is widely accepted that the minimum is caused by the existence of a highly surface-active impurity in the soap solution [49]. Hence, the surface tension of the different soap solutions depicts that LX has the best and LFBY has the least cleansing action.

3.16. Antibacterial Sensitivity Screening. Human skin is a rich habitat of pathogenic microbes. Antibacterial screening of soap solutions was performed at four different concentrations and the data revealed pathetic conditions that contrasted with their commercial advertisements. In vitro antibacterial study of soaps was conducted against three different bacterial pathogens such as S. aureus, E. coli, and $P$. vulgaris by the standard Kirby-Bauer paper disc diffusion technique [50]. The antibacterial data are summarized in 


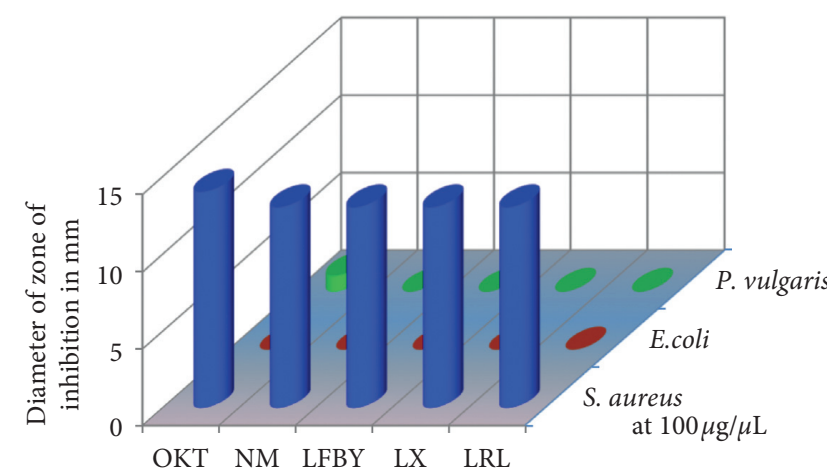

(a)

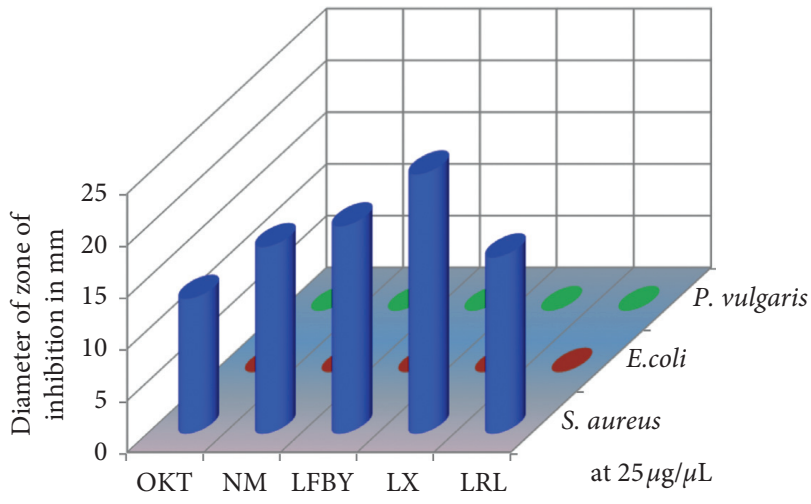

(c)

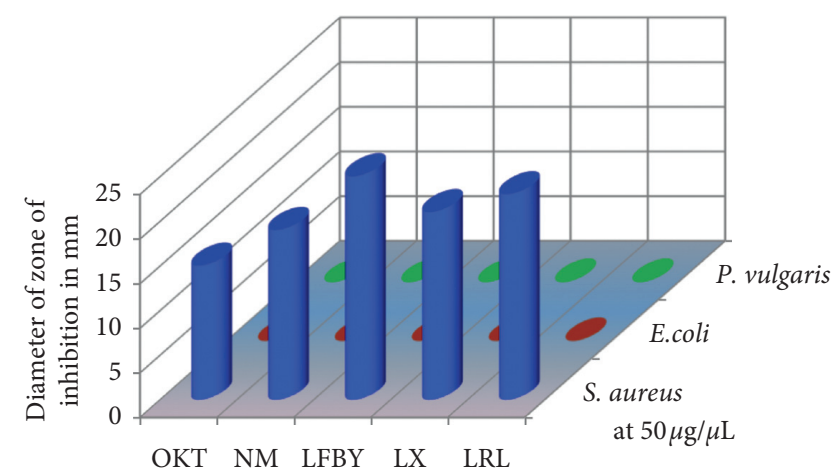

(b)

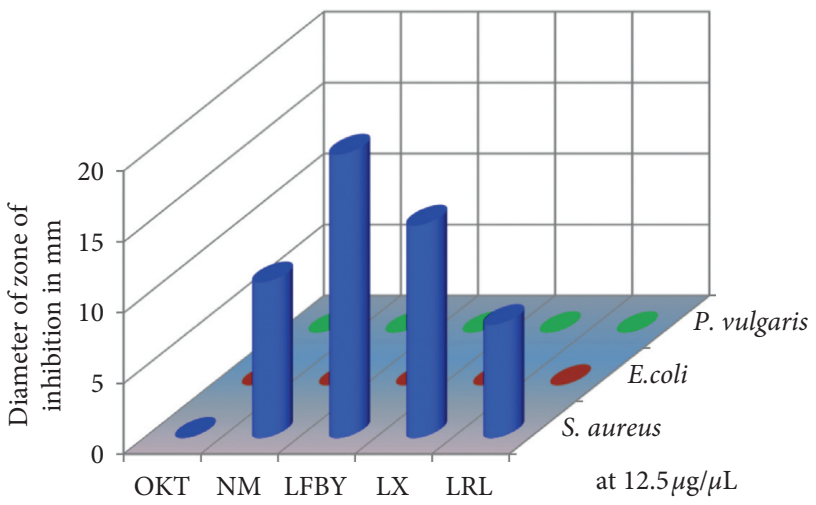

(d)

FIgURE 19: The antibacterial action of the soaps against the pathogenic bacteria at four different concentrations.

Table 5, and the results are evaluated on bar graph (Figure 19). LFBY soap revealed satisfactory bacterial growth inhibition even at the lowest tested concentration relative to other soaps. Soap solutions at $100 \mu \mathrm{g} / \mu \mathrm{L}$ concentration became very concentrated and were soon converted to semisolid form and were unable to show the expected antibacterial action. All soaps showed their highest action at $50 \mu \mathrm{g} / \mu \mathrm{L}$ except LX, whose highest activity was shown at $25 \mu \mathrm{g} / \mu \mathrm{L}$. From this study, looking at the data against $S$. aureus, we can say that the use of small amounts of LFBY and LX soaps can kill bacteria, among others. The high action shown by soap at $50 \mu \mathrm{g} / \mu \mathrm{L}$ (and $25 \mu \mathrm{g} / \mu \mathrm{L}$ for $\mathrm{LX}$ ) can be argued towards the superior diffusion capacity of soap at high concentrations. The antibacterial action shown by herbal soaps is less than that of other soaps, but not so low, and may still replace chemically manufactured soaps, where bacteria are more likely to become resistant.

The excessive use of antibiotics for the control of infections has created some exceptional conditions for developing resistant elements in bacterial populations [51]. In this era, where the strongest of antibiotics are failing to kill pathogenic bacteria, now becoming superbugs, it may not be a big surprise to see the low inactivity of toilet soaps. The socalled continued use of antibacterial soap is itself supportive of being resistant to bacteria [4]. In the present study, among the bacteria encountered, two are seen to be completely resistant to any soap, whereas $S$. aureus is seen to be susceptible. Looking at the literature and current tests, only a few bacteria are seen to be susceptible to the most common form of antibacterial agents and are in the same race to be resistant. Not only do we take antibiotics or animal feeds with dietary antibiotics (to get healthy and support rapid growth), contact with any creature with resistant bacteria can supply us with those bacteria that eventually turn the harmless bacteria into resistant [52]. More surprisingly, any form of the cosmetic product, in which manufacturers proudly advertise their product as pathogenic slayer can usually induce and support the resistance in bacteria. Even though antibacterial soaps can protect patients from the transfer of opportunistic pathogens, prolonged use of antiseptic soaps can eliminate both beneficial and harmful bacteria, making the skin more vulnerable to pathogenic microorganisms and ultimately antibacterial resistance. Rather the use of herbal soaps is supported [4].

\section{Conclusion}

The cleaning action of soaps is associated with the surface tension as well as CMC. The CMC calculated from the surface tension and conductivity of soaps matched each other. In comparison with other investigated soaps, the CMC is more in the LX and has the lowest value of surface tension. Higher CMC and lower surface tension of LX always give more micelles. Hence, the solution of LX soap is the effective cleaning solution because of more micelles. Similarly, the antibacterial potency of LFBY was found higher than other soaps. Based on these studies, we can simply take LFBY at the highest rank. The present 
investigation reveals solution property study which controls the cleansing and removal of dirt and bacteria. The bioactive ingredients present in them provide antibacterial potency to cure various skin problems caused by bacterial pathogens. The antibacterial action of the herbal soap is also satisfactory and can replace the chemical soaps in needed times. The surface tension data of the complex system give a very good fitting of the experimental data of surface tension with the help of a theoretical model, indicating that the presence of surface-active agents is more in the soaps. Our findings may serve as a landmark for selecting appropriate soap for the society and also motivate to investigate further on the experimental data of surface tension and conductivity for soaps with more theoretical models.

\section{Data Availability}

The graphical data of ingredients of various soaps selected for antibacterial assessment supporting this paper have been uploaded as electronic supplementary material.

\section{Conflicts of Interest}

The authors declare that they have no conflicts of interest.

\section{Supplementary Materials}

S1 Table: ingredients of various soaps selected for antibacterial assessment. (Supplementary Materials)

\section{References}

[1] O. M. Ogba, P. E. Asukwo, and I. B. Otu-Bassey, "Assessment of bacterial carriage on the hands of primary school children in Calabar municipality, Nigeria," Biomedical Dermatology, vol. 2, no. 6, pp. 1-7, 2018.

[2] T. Yahaya, J. Okpuzor, and E. O. Oladele, "Investigation of toxicity of detergents," Journal of Environmental Science and Technology, vol. 4, no. 6, pp. 638-645, 2011.

[3] S. A. Kim, H. Moon, K. Lee, and M. S. Rhee, "Bactericidal effects of triclosan in soap both in vitro and in vivo," The Journal of Antimicrobial Chemotherapy, vol. 70, pp. 33453352, 2015.

[4] C. N. Obi, "Antibacterial activities of some medicated soaps on selected human pathogens," American Journal of Microbiological Research, vol. 2, no. 6, pp. 178-181, 2014.

[5] J. L. Fuls, N. D. Rodgers, G. E. Fischler et al., "Alternative hand contamination technique to compare the activities of antimicrobial and nonantimicrobial soaps under different test conditions," Applied and Environmental Microbiology, vol. 74, no. 12, pp. 3739-3744, 2008.

[6] S. Riaz, A. Ahmad, and S. Hasnain, "Antibacterial activity of soaps against daily encountered bacteria," African Journal of Biotechnology, vol. 8, no. 8, pp. 1431-1436, 2009.

[7] A. E. Aiello, E. L. Larson, and S. B. Levy, "Consumer antibacterial soaps: effective or just risky?" Clinical Infectious Diseases, vol. 45, no. 2, pp. S137-S147, 2007.

[8] A. E. Aiello, R. M. Coulborn, V. Perez, and E. L. Larson, "Effect of hand hygiene on infectious disease risk in the community setting: a meta-analysis," American Journal of Public Health, vol. 98, no. 8, pp. 1372-1381, 2008.
[9] B. Michaels, V. Gangar, A. Schultz et al., "Water temperature as a factor in handwashing efficacy," Food Service Technology, vol. 2, no. 3, pp. 139-149, 2003.

[10] S. Bidawid, N. Malik, O. Adegbunrin, S. A. Sattar, and J. M. Farber, "Norovirus cross-contamination during food handling and interruption of virus transfer by hand antisepsis: experiments with feline calicivirus as a surrogate," Journal of Food Protection, vol. 67, no. 1, pp. 103-109, 2004.

[11] T. B. Hansen and S. Knochel, "Image analysis method for evaluation of specific and non-specific hand contamination," Journal of Applied Microbiology, vol. 94, no. 3, pp. 483-494, 2003.

[12] N. Tabassum and M. Hamdani, "Plants used to treat skin diseases," Pharmacognosy Reviews, vol. 8, no. 15, pp. 52-60, 2014.

[13] K. Kon and M. Rai, Antibiotic Resistance Mechanisms and New Antimicrobial Approaches, Sara Tenney Academic Press, Washington, DC, USA, 2016.

[14] A. Chandrasekara and F. Shahidi, "Herbal beverages: bioactive compounds and their role in disease risk reduction-a review," Journal of Traditional and Complementary Medicine, vol. 8, no. 4, pp. 451-458, 2018.

[15] O. Atolani, E. T. Olabiyi, A. A. Issa et al., "Green synthesis and characterisation of natural antiseptic soaps from the oils of underutilised tropical seed," Sustainable Chemistry and Pharmacy, vol. 4, pp. 32-39, 2016.

[16] A. Fathi-Azarbayjani and A. Jouyban, "Surface tension in human pathophysiology and its application as a medical diagnostic tool," BioImpacts, vol. 5, no. 1, pp. 29-44, 2015.

[17] M. O. Adebajo, M. S. Akanni, and R. L. Frost, "Effect of palm kernel oil extraction method on the electrical conductance of nigerian traditional soaps in alcohols," Journal of Surfactants and Detergents, vol. 7, no. 1, pp. 81-85, 2004.

[18] M. O. Adebajo and M. Sola Akanni, "The electrical conductance and viscosity of Nigerian traditional soaps in alcoholic media," Colloids and Surfaces A: Physicochemical and Engineering Aspects, vol. 194, no. 1-3, pp. 97-110, 2001.

[19] T. P. Niraula, S. K. Chatterjee, and A. Bhattarai, "Micellization of sodium dodecyl sulphate in presence and absence of alkali metal halides at different temperatures in water and methanol-water mixtures," Journal of Molecular Liquids, vol. 250, pp. 287-294, 2018.

[20] K. M. Sachin, S. A. Karpe, M. Singh, and A. Bhattarai, "Selfassembly of sodium dodecylsulfate and dodecyltrimethylammonium bromide mixed surfactants with dyes in aqueous mixtures," Royal Society Open Science, vol. 6, no. 3, 2019.

[21] T. Mukhim and K. Ismail, "Aggregation, counter ion binding and adsorption behaviors of cetylpyridinium chloride in water/glycerol media at $25^{\circ} \mathrm{C}$, Journal of Surfactants and Detergents, vol. 15, no. 1, pp. 47-51, 2012.

[22] P. A. Koya, K. -ud-Din, and K. Ismail, "Micellization and thermodynamic parameters of butanediyl-1,4- bis(tetradecyldimethylammonium Bromide) gemini surfactant at different temperatures: effect of the addition of 2-methoxyethanol," Journal of Solution Chemistry, vol. 41, no. 8, pp. 1271-1281, 2012.

[23] A. Bhattarai, K. Pathak, and B. Dev, "Cationic and anionic surfactants interaction in water and methanol-water mixed solvent media," Journal of Molecular Liquids, vol. 229, pp. 153-160, 2017.

[24] J. M. del Rio, G. Prieto, F. Sarmiento, and V. Mosquera, "Thermodynamics of micellization of 
N-Octyltrimethylammonium bromide in different media," Langmuir, vol. 11, no. 5, pp. 1511-1514, 1995.

[25] S. Kolay, K. K. Ghosh, and P. Quagliotto, "Micellization behavior of [C16-12-C16], 2Br-gemini surfactant in binary aqueous-solvent mixtures," Colloids and Surfaces A: Physicochemical and Engineering Aspects, vol. 348, no. 1-3, pp. 234-239, 2009.

[26] P. Carpena, J. Aguiar, P. Bernaola-Galván, and C. Carnero Ruiz, "Problems associated with the treatment of Conductivity-Concentration data in surfactant solutions: simulations and experiments," Langmuir, vol. 18, no. 16, pp. 6054-6058, 2002.

[27] W. H. Press, S. A. Teukolsky, W. Vetterling, and B. Flannery, Numerical Recipes the Art of Scientific Computing, Cambridge University Press, Cambridge, UK, 2007.

[28] D. Ng, S. Kundu, M. Kulkarni, and H. Liang, "Role of surfactant molecules in post-CMP cleaning," Journal of the Electrochemical Society, vol. 155, no. 2, pp. 64-68, 2008.

[29] P. Barkvoll, "[Should toothpastes foam? Sodium lauryl sulfate--a toothpaste detergent in focus]," Den Norske Tannlaegeforenings Tidende, vol. 99, no. 3, pp. 82-84, 1989.

[30] N. Dubey, "CTAB aggregation in solutions of higher alcohols: thermodynamic and spectroscopic studies," Journal of Molecular Liquids, vol. 184, pp. 60-67, 2013.

[31] B. Kronberg, M. Costas, and R. Silveston, “Thermodynamics of the hydrophobic effect in surfactant solutions: micellization and adsorption," Pure and Applied Chemistry, vol. 67, no. 6, pp. 897-902, 1995.

[32] K. Manna and A. K. Panda, "Physicochemical studies on the interfacial and micellization behavior of CTAB in aqueous polyethylene glycol media," Journal of Surfactants and Detergents, vol. 14, no. 4, pp. 563-576, 2011.

[33] I. Mukherjee, S. P. Moulik, and A. K. Rakshit, "Tensiometric determination of Gibbs surface excess and micelle point: a critical revisit," Journal of Colloid and Interface Science, vol. 394, no. 1, pp. 329-336, 2013.

[34] A. Pradhan and A. Bhattacharyya, "Shampoos then and now: synthetic versus natural," Journal of Surface Science and Technology, vol. 30, no. 1-2, pp. 59-76, 2014.

[35] S. K. Shah, S. K. Chatterjee, and A. Bhattarai, "The effect of methanol on the micellar properties of Dodecyltrimethylammonium bromide (DTAB) in aqueous medium at different temperatures," Journal of Surfactants and Detergents, vol. 19, no. 1, pp. 201-207, 2016.

[36] M. Abdul Rub, "Aggregation and interfacial phenomenon of amphiphilic drug under the influence of pharmaceutical excipients (green/biocompatible gemini surfactant)," PLoS One, vol. 14, no. 2, 2019.

[37] T. Chakraborty, I. Chakraborty, and S. Ghosh, "Sodium Carboxymethylcellulose-CTAB interaction: a detailed thermodynamic study of Polymer-Surfactant interaction with opposite charges," Langmuir, vol. 22, no. 24, pp. 9905-9913, 2006.

[38] S. S. Borse, T. J. Patil, and M. S. Borse, "Effect of tuned head polarity of cetyl trimethyl ammonium bromide on their physicochemical properties," Tenside Surfactants Detergents, vol. 51, no. 3, pp. 267-273, 2014.

[39] M. J. Rosen, Micelle Formation by Surfactants, John Wiley \& Sons, Hoboken, NJ, USA, 3rd edition, 2012.

[40] R. Patel, A. B. Khan, N. Dohare, M. Maroof Ali, and H. K. Rajor, "Mixed micellization and interfacial properties of ionic liquid-type imidazolium gemini surfactant with amphiphilic drug amitriptyline hydrochloride and its thermodynamics," Journal of Surfactants and Detergents, vol. 18, no. 5, pp. 719-728, 2015.

[41] P. S. Niranjan and S. K. Upadhyay, "Interaction of polyacrylamide with conventional anionic and gemini anionic surfactants," Journal of Dispersion Science and Technology, vol. 32, no. 1, pp. 109-113, 2010.

[42] U. R. Dharmawardana, S. D. Christian, E. E. Tucker, R. W. Taylor, and J. F. Scamehorn, "A surface tension method for determining binding constants for cyclodextrin inclusion complexes of ionic surfactants," Langmuir, vol. 9, no. 9, pp. 2258-2263, 1993.

[43] V. B. Fainerman and R. Miller, "Surface tension isotherms for surfactant adsorption layers including surface aggregation," Langmuir, vol. 12, no. 25, pp. 6011-6014, 1996.

[44] A. J. Prosser and E. I. Franses, "Adsorption and surface tension of ionic surfactants at the air-water interface: review and evaluation of equilibrium models," Colloids and Surfaces A: Physicochemical and Engineering Aspects, vol. 178, no. 1-3, pp. 1-40, 2001

[45] A. Zdziennicka and B. Jańczuk, "Properties of n-octyl- $\beta$-dglucopyranoside and sodium dodecylsulfate mixed monolayer at the water-air interface," Journal of Molecular Liquids, vol. 280, pp. 259-267, 2019.

[46] C. J. van Oss, Interfacial Forces in Aqueous Media, CRC Press, New York, NY, USA, 1994.

[47] M. R. Bresler and J. P. Hagen, "Surfactant adsorption: a revised physical chemistry lab," Journal of Chemical Education, vol. 85, no. 2, pp. 269-271, 2008.

[48] C. Zhang, T. Geng, Y. Jiang, L. Zhao, H. Ju, and Y. Wang, "Impact of $\mathrm{NaCl}$ concentration on equilibrium and dynamic surface adsorption of cationic surfactants in aqueous solution," Journal of Molecular Liquids, vol. 238, pp. 423-429, 2017.

[49] S.-Y. Lin, Y.-Y. Lin, E.-M. Chen, C.-T. Hsu, and C.-C. Kwan, "A study of the equilibrium surface tension and the critical micelle concentration of mixed surfactant solutions," Langmuir, vol. 15, no. 13, pp. 4370-4376, 1999.

[50] A. W. Bauer, W. M. M. Kirby, J. C. Sherris, and M. Turck, "Antibiotic susceptibility testing by a standardized single disk method," American Journal of Clinical Pathology, vol. 45, no. 4_ts, pp. 493-496, 1966.

[51] E. D. Brown and G. D. Wright, "Antibacterial drug discovery in the resistance era," Nature, vol. 529, no. 7586, pp. 336-343, 2016.

[52] M. Barza, S. Gorbach, and S. J. DeVincent, "Introduction," Clinical Infectious Diseases, vol. 34, no. s3, pp. S71-S72, 2002. 